\title{
Why a change of diagnosis shouldn't matter . . . but it does
}

From loss of identity to social stigma, Suzy Syrett describes the hidden impact of a change to her mental health diagnosis

Suzy Syrett

I'm 45 years old and since 1994 I've lived with three different psychiatric diagnoses; bipolar disorder (1994-2008), depression and psychosis (2008-16), and (2016-present) personality disorder not otherwise specified.

\section{Identity conflicts}

Each new diagnosis radically shifted how I interpreted the symptoms I was experiencing, the prognosis I was told to expect, and the treatments I was receiving. It was also a shock to witness how much my diagnosis had become integrated into others' perception of me. Unintended but hurtful comments such as, "Can I just say you still have bipolar? My friends don't mind that one" are commonplace. To say these experiences didn't impact on my understanding of who I am, and why, would be ridiculous.

\section{Confusion and change}

Having information about my new diagnosis was useful, but I found little support to help me deal with how it feels to undergo that change. I'd describe the process as being similar to grief because I felt that as I said farewell to one diagnosis it was replaced by a more stigmatising one. And there can be implications for job applications, current employment, or continuing entitlement to the personal independence payment, all of which bring stresses of their own.

\section{Treatment and support}

With each change of diagnosis I had to deal with the realisation that I might have been on the wrong medications for years and the concern these drugs might be removed. Many psychiatric drugs have the potential for damaging physiological impact, which is worrying enough, but for me the more pressing concern was coming off a drug that I believed was helping me. Glasgow's bipolar support group played a huge part in helping me accept the impact of my illness in 1994. When my diagnosis was changed my interpretation was that I could no longer attend that group. Having bipolar was no longer a story that I thought
I could share in or offer my perspective on. Part of any support group's role is to bring inclusivity to those who already feel separated from society and so feeling excluded from such a group was a doubly miserable process.

\section{Problems of miscommunication}

The challenges of hearing a diagnosis of personality disorder were even more fundamental and corrosive than those I faced after my previous change of diagnosis. This change of diagnosis came without warning and during the shock of that appointment it seemed to me that the suffering I had experienced-never mind that my family and friends-was all my fault. I was to blame.

Fortunately, my psychiatrist arranged a second appointment to help clear up some of those questions. That helped a lot. But there was still the confusion of continuing to experience symptoms that didn't fit my new diagnosis.

\section{Trust and other issues}

"Do my community mental health team believe me?" is never a thought I want to have. I have an excellent team and being assured they all knew of my new diagnosis, would support me through the process of change, and that they would always take me seriously when I ask for help regardless of symptom was key. If I had a reason to doubt them, or even worse, if I felt that they doubted me, then that relationship, as concrete and enduring as it is, would be destroyed.

\section{Delivering change}

We all face decisions in life that bring changes that can be hard to cope with. Imagine dealing with an enforced change of great impact that you felt you had no involvement in? Psychiatric diagnoses have always seemed unquestionable facts and not open to debate. Making a diagnosis can be challenging, but wouldn't it be at least as challenging for a patient to accept a change of diagnosis? Discussing why the change is required 
might help your patient accept their new diagnosis and associated change of treatment. Presenting unexpected and unsubstantiated change could risk damaging the trust between your patient and you, and ultimately the diagnostic method.

Plenty of information is available for most diagnoses, but what I think are absent are sources of support on how to cope with the distinct process of change. I'd love readers to suggest how we can better support the thousands of patients who, like me, find themselves unwittingly experiencing this often unhappy, complicated, and multifaceted process.

\section{What you need to know}

- Changing patients' diagnoses can affect their personal, professional, social, financial, and emotional lives

- Offer patients discussions about why the change in their diagnoses and treatments is being proposed to build trust and feelings of consideration

- Encourage discussion between doctor/community psychiatric nurse and patient of why changes in diagnoses can happen.

\section{Education into practice}

- Can you think of a time when you changed a patient's diagnosis? What were the main reasons for doing so? How did it go? Does this article offer ideas on how you might modify your approach?

- Changes to diagnosis might alter patients' identity or support systems. How might you help patients navigate this time?

- Diagnoses can evolve, change, or be uncertain. To what extent do you share the uncertainty about diagnosis with patients? Would some patients benefit? Would some patients struggle? Why?

Competing interests: I have read and understood BMJ policy on declaration of interests and declare the following: none. SS is a peer researcher in the department of mental health and wellbeing at the University of Glasgow.

Provenance and peer review: Commissioned, based on an idea from the author; not externally peer reviewed.

Published by the BMJ Publishing Group Limited. For permission to use (where not already granted under a licence) please go to http://group.bmj.com/group/rights-licensing/ permissions 